\title{
Fenestrated A1 segment of right anterior cerebral artery associated to duplicated anterior communicating artery
}

\author{
Ildo Sonda ${ }^{1,2}$, Luciano Silveira Basso ${ }^{1}$ \\ ${ }^{1}$ Department of Human Anatomy, Medical School of University of Caxias do Sul, Caxias do Sul, Brazil \\ ${ }^{2}$ Department of Neurosurgery, General Hospital of Caxias do Sul, Caxias do Sul, Brazil
}

\begin{abstract}
We present a case of fenestrated anterior cerebral artery associated to duplicated anterior communicating artery found during a routine dissection of the brain in a male human body. Fenestrations of the A1 segment of the anterior cerebral artery are rare, especially if associated to a duplicated anterior communicating artery. To our knowledge, this is the second reported case in the literature. We also present a brief review of the surgical importance of this anomaly.
\end{abstract}

Keywords: A1 segment; anterior cerebral artery; anterior communicating artery

Anatomy 2015;9(1):42-44 C2015 Turkish Society of Anatomy and Clinical Anatomy (TSACA)

\section{Introduction}

The cerebral arterial circle, also known as circle of Willis (CW), was described by Thomas Willis in 1664, but in majority of cases there are some variations from the original definition. The $\mathrm{CW}$ is considered normal when a closed circuit in which the fluid can flow from any entrance point and return to that point through their vessels, without supernumerary vessels, with the usual anterior cerebral arteries pairs, and the mature vessels with more than $1 \mathrm{~mm}$ in their outside diameter. ${ }^{[1]}$

Fenestrations of the A1 segment of the anterior cerebral artery (ACA) are a rare cause of asymmetry in the CW. Fawcett and Blachford ${ }^{[2]}$ described only one case in a sample of 700 specimens, that corresponds to $0.14 \%$, it was the right artery which was affected. In the same study, the duplicated anterior communicating artery (ACoA) was found in $7.2 \%$ of the specimens.

Gurdal et al..$^{[3]}$ described a duplicated ACoA associated to a small fenestration on ACA at the level of the ACoA. In our review, we did not find other reports of these two variations associated, and to our knowledge this is the second reported case.

\section{Case Report}

During a routine dissection of the brain of a 52-year-old male cadaver, a complete but anomalous $\mathrm{CW}$ was detected. The posterior circulation, consisting of the posterior cerebral arteries, the posterior communicating arteries and the basilar artery, was complete and symmetric. In the anterior circulation, a fenestrated A1 segment of right ACA associated to a duplicated ACoA was found (Figures $\mathbf{1 a}$ and $\mathbf{b}$ ). Both ACoA were connected to the medial surface of the medial branch of the fenestrated A1 segment of right ACA. No aneurysms or hypoplasia were found in the CW.

\section{Discussion}

Fenestration of the A1 segment might occur due to the absence of fusion of the plexiform anastomosis which was present in the distal primitive ACA during the 18 to $43 \mathrm{~mm}$ stage of the embryo. This failure would possibly increase blood flow in one of the A1 segments because of the contralateral A1 hypoplasia. This results in increased hemodynamic stress on the ipsilateral A1 segment that can cause a fenestration and, also, an aneurysm formation on the fenestrated A1 segment. The hypoplasia of one side of the first 

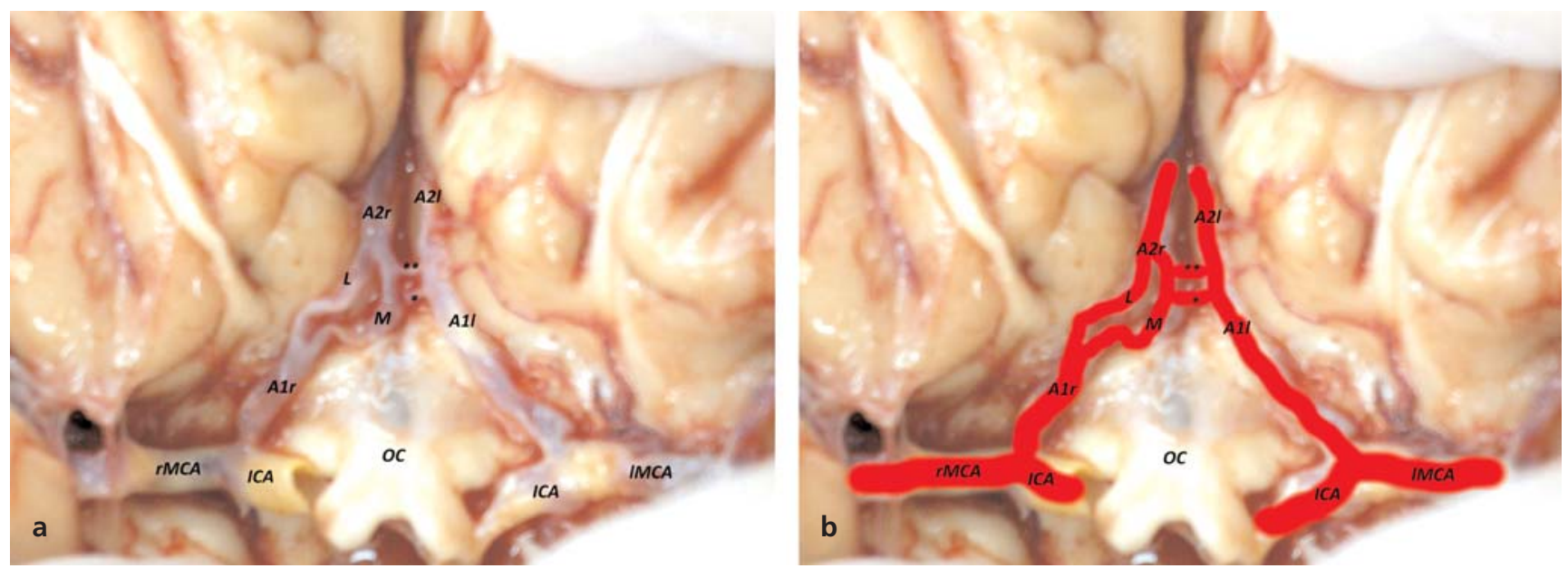

Figure 1. (a) Fenestrated right anterior cerebral artery and duplicated anterior communicating artery. (b) Schematic illustration of the fenestrated right anterior cerebral artery and duplicated anterior communicating artery. *: first anterior communicating artery; **: second anterior communicating artery; A1l: first segment of left anterior cerebral artery; A1r: first segment of right anterior cerebral artery; A2l: second segment of left anterior cerebral artery; A2r: second segment of right anterior cerebral artery; ICA: internal carotid artery; L: lateral branch of fenestrated A1 segment; M: medial branch of fenestrated A1 segment; IMCA: left middle cerebral artery; rMCA: right middle cerebral artery; OC: optic chiasm.

segment of the ACA is a common anatomical variation, presented in $7-10 \%$ of the population. ${ }^{[4]}$

Aktüre et al., in their review, have found 76 reported cases of A1 fenestrations in the literature, 5 of these cases had bilateral bifurcation. ${ }^{[5]} 19$ cases of aneurysms associated with fenestrated A1 segment was described in the literature. All cases represented saccular type of aneurysms, and $79 \%$ of the patients had subarachnoid hemorrhage. 15 of those cases were treated by clipping with good recovery in $60 \%$ of the patients. 3 patients were treated with coiling, two of them ruptured, and all presented good recovery. ${ }^{[6]}$

Kwon et al ${ }^{[6]}$ classified fenestrated A1 aneurysm into three subtypes based on the location of aneurysms associated with $\mathrm{A} 1$ fenestrations. Type I is located on the proximal end of the A1 fenestration, which corresponds to $82 \%$ of the cases. Type II aneurysm arises from the trunk of the fenestrated A1, corresponding to $12 \%$ of the cases. Type III are multiple aneurysms in the fenestration, including one at the proximal end and another at the posterior aspect of the fenestrated artery, with a single case reported in the literature. ${ }^{[7]}$

Multiple aneurysms were shown in $16 \%$ of patients with fenestrated A1 aneurysms, which was comparable to approximately $15-20 \%$ of incidence of multiplicity in all patients with aneurysms. ${ }^{[8-10]}$ Therefore a fenestrated A1 aneurysm may not be associated with the occurrence of multiple aneurysms.

Treatment of aneurysms derived from a fenestrated artery may be more challenging because the fenestrations provide specific difficulties. The A1 segment generally supplies the optic chiasm, anterior third ventricle and hypothalamus, medial third of the anterior commissure, caudate head, globus pallidus, anterior limb of the internal capsule and rostral thalamus. Therefore, the origin of the A1 perforators in a fenestrated A1 segment is important on planning endovascular or open surgical approaches for the treatment of associated aneurysms. If occlusion of the fenestrated arm is being considered as the treatment, the origins of the major perforators should be clearly identified. The majority of the normal A1 perforators originate from the lateral surface of the $\mathrm{A} 1$ as described by Perlmutter and Rhoton. ${ }^{[11]}$

The complex anatomy and angulation of the fenestrated segments, the inability to unequivocally establish the ability of individual fenestrated A1 segments to adequately support blood flow to both distal ACAs, the fear of compromising perforating vessels and the risk of dislodging a thrombus, increase the degree of difficulty for surgery, as well for endovascular treatment. ${ }^{[12]}$

\section{Conclusion}

An appropriate knowledge of cerebrovascular anatomy is required for microneurosurgery, especially in aneurysm surgeries. Fenestrated A1 segment is considered a risk factor for the development of aneurysm, since saccular brain aneurysms usually arise from the arterial bifurcations where the blood flow establishes the greatest hemodynamic stress. 


\section{References}

1. Nordon DG, Rodrigues Junior OF. Variations in the brain circulation - the circle of Willis. J Morphol Sci 2012;29:243-7.

2. Fawcett E, Blachford JV. The circle of Willis: an examination of 700 specimens. J Anat Physiol 1905;40:63-70.

3. Gurdal E, Cakmak O, Yalcinkaya M, Uzun I, Cavdar S. Two variations of the anterior communicating artery: a clinical reminder. Neuroanatomy 2004;3:32-4.

4. Handa J, Nakasu Y, Matsuda M, Kyoshima K. Aneurysms of the proximal anterior cerebral artery. Surg Neurol 1984;22:486-90.

5. Aktüre E, Arat A, Niemann DB, Salamat MS, Baskaya MK. Bilateral A1 fenestrations: report of two cases and literature review. Surg Neurol Int 2012;3:43.

6. Kwon WK, Park KJ, Park DH, Kang SH. Ruptured saccular aneurysm arising from fenestrated proximal anterior cerebral artery: case report and literature review. J Korean Neurosurg Soc 2013;53:293-6.
7. Mitsuhara T, Sakamoto S, Kiura Y, Kurisu K. Endovascular coil embolization for ruptured kissing aneurysms associated with A1 fenestration. Surg Neurol Int 2011;2:85.

8. Inagawa $T$. Incidence and risk factors for multiple intracranial saccular aneurysms in patients with subarachnoid hemorrhage in Izumo City, Japan. Acta Neurochir (Wien) 2009;151:1623-30.

9. Ostergaard JR, Høg E. Incidence of multiple intracranial aneurysms. Influence of arterial hypertension and gender. J Neurosurg 1985;63: $49-55$.

10. Wiebers DO, Whisnant JP, O'Fallon WM. The natural history of unruptured intracranial aneurysms. N Engl J Med 1981;304:696-8.

11. Perlmutter D, Rhoton AL. Microsurgical anatomy of the anterior cerebral anterior communicating-recurrent artery complex. J Neurosurg 1976;45:259-72.

12. Rajan K, Sanjay B, Kamlesh S, Rabi S, Awadhesh J. Trilobulated fusiform aneurysm from proximal fenestrated segment of dominant A1 causing subarachnoid hemorrhage. Neurol India 2013;61: $315-7$.

Correspondence to: Luciano Silveira Basso, MD

Rua Os 18 do Forte, 718/305, Bairro Lourdes, CEP 95020-472

Caxias do Sul, Rio Grande do Sul, Brasil

Phone: +54 35376024

e-mail: lucianosbasso@gmail.com

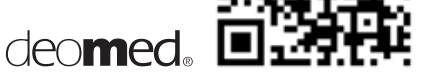

Conflict of interest statement: No conflicts declared.

This is an open access article distributed under the terms of the Creative Commons Attribution-NonCommercial-NoDerivs 3.0 Unported (CC BY-NCND3.0) Licence (http://creativecommons.org/licenses/by-nc-nd/3.0/) which permits unrestricted noncommercial use, distribution, and reproduction in any medium, provided the original work is properly cited. Please cite this article as: Sonda I, Basso LS. Fenestrated A1 segment of right anterior cerebral artery associated to duplicated anterior communicating artery. Anatomy 2015;9(1):42-44. 